\title{
The National Health and Medical Research Council Road Map: a strategic framework for improving Aboriginal and Torres Strait Islander health through research
}

Felicia R Fletcher, Cindy Shannon, Terry E Dunbar, for the Aboriginal and Torres Strait Islander Health and Research Advisory Committee*

\author{
What impact has the NHMRC Road Map had on Aboriginal and Torres Strait Islander health? \\ A review process now underway aims to find out
}

$\mathrm{T}$ here are significant disparities in health status between Aboriginal and Torres Strait Islander peoples and other Australians across the life cycle, including lower birthweight, higher death rates, lower life expectancy, and a much higher incidence of a range of illnesses that affect social and emotional wellbeing. ${ }^{1}$

The National Health and Medical Research Council (NHMRC) is Australia's peak body for supporting health and medical research. It is also responsible for developing health advice for the Australian community, health professionals and government, and advising on ethical behaviour both in health care and in the conduct of health and medical research.

The role of the NHMRC in the Australian Government's strategic framework for improving the health status of Aboriginal and Torres Strait Islander peoples includes:

- developing culturally appropriate health advice and guidelines;

- funding research to improve the health and wellbeing of Aboriginal and Torres Strait Islander peoples;

- providing information on the ethical considerations that arise in research;

- supporting Aboriginal and Torres Strait Islander peoples in participating in research capacity building; and

- commissioning health and medical research in priority areas.

\section{The Road Map}

In 2002, the NHMRC promoted the development of the Aboriginal and Torres Strait Islander Research Agenda Working Group "Road Map" - a strategic framework to identify agreed national research priorities in Aboriginal and Torres Strait Islander health. More than 250 people had direct input into the development of this framework through attendance at four workshops held in Perth, Darwin, Brisbane and Melbourne. Representatives were drawn from all states and territories and included a balance of Aboriginal and Torres Strait Islander and non-Indigenous participants. Additional input was received from 23 organisations through a written submission process. This process of open consultation and discussion highlighted a number of areas where priority research was urgently needed, to complement existing researchdriven programs.

\footnotetext{
* The Aboriginal and Torres Strait Islander Health and Research Advisory Committee members are: Professor Cindy Shannon (Chair), Professor lan Anderson, Dr Ngiare Brown, Professor Yvonne Cadet-James, Associate Professor Terry Dunbar, Associate Professor Jacinta Elston, Associate Professor Lisa Jackson-Pulver, Mr Daniel McAullay, Dr Mark Wenitong and Dr Tim Williams.
}

\begin{abstract}
The Road Map's six research themes ${ }^{2}$
1. Descriptive research which outlines patterns of health risk, disease and death. This information should be used to inform the development of sound preventive, early diagnosis and treatmentbased interventions which are likely to result in meaningful health gain for Aboriginal and Torres Strait Islander peoples.

2. A research focus on the factors and processes that promote resilience and wellbeing - in particular, but not exclusively, during the periods of pregnancy, infancy, childhood and adolescence - and form the basis of good health throughout the lifespan.

3. A focus on health services research which describes the optimum means of delivering preventive, diagnostic and treatment-based health services and interventions to Aboriginal and Torres Strait Islander peoples.

4. A focus on the association between health status and health gain and policy and programs that lie outside the direct influence of the health sector.

5. A focus on engaging with research and action in previously under-researched Aboriginal and Torres Strait Islander populations and communities.

6. Development of the nation's Aboriginal and Torres Strait Islander health research capacity (including training Aboriginal and Torres Strait Islander researchers) and ethical health research practice in relation to Aboriginal and Torres Strait Islander communities.
\end{abstract}

The resulting Road Map outlines six research themes crucial to achieving substantial health gains for Aboriginal and Torres Strait Islander peoples (Box). ${ }^{2}$

The overall objective of the Road Map has been:

to advise Aboriginal and Torres Strait Islander communities throughout Australia on the achievement and maintenance of the highest practicable standards of individual and public health, and to foster research in the interests of improving those standards. ${ }^{2}$

\section{Underlying principles of the Road Map}

The Road Map was implemented in 2002, advocating research and development underpinned by the following principles:

- Health is not just the physical wellbeing of the body but a whole-of-life and unending phenomenon;

- Community involvement is integral to the development, conduct and communication of research;

- Research must be conducted ethically $y^{3-5}$ and be of practical value to Aboriginal and Torres Strait Islander peoples and their service providers;

- Communication of research plans, progress and results is essential; 


\section{RESEARCH ENTERPRISE}

- It is important to support research, including enhancing the development of skills, knowledge and capacity in the Aboriginal and Torres Strait Islander research workforce; and

- It is important to identify "positive models" or examples of success.

\section{NHMRC-funded research}

Within the framework of the Road Map research themes, the NHMRC has initiated programs that aim to improve the health of Aboriginal or Torres Strait Islander people or build capacity in the Aboriginal and Torres Strait Islander health research sector. These programs currently include:

- the Indigenous Short-Term Exchange/Study Scheme;

- the International Collaborative Indigenous Health Research Partnership;

- Training Scholarships for Indigenous Health Research; and

- the Aboriginal and Torres Strait Islander Health Research Fellowship.

Funding is also allocated to research on the health of Aboriginal or Torres Strait Islander people through project grants and in response to specific needs, including the Capacity Building Grants in Population Health Research initiative and the Healthy Start to Life for Aboriginal and Torres Strait Islander Communities initiative.

Based on the research outcomes reported to date, the NHMRC has been able to develop some understanding of the Road Map's impact by tracking the extent of employment of Aboriginal or Torres Strait Islander people on projects, the numbers and types of publications and presentations that have resulted from research, the effectiveness of research methodologies, and the level and context of researchers' relationships with communities.

\section{Review of the Road Map}

The Road Map continues to be part of a strategic research framework that commits the NHMRC to all research relevant to health - biomedical, clinical, public health and health services and consultation with all levels of government, the health and medical research sector, and the community about priority research areas

During its development in 2002, it was anticipated that the Road Map would be reviewed in 2007. The review is being undertaken by the NHMRC in consultation with its key advisory committee on Indigenous health issues, the Aboriginal and Torres Strait Islander Health and Research Advisory Committee, chaired by Professor Cindy Shannon.

Consultation workshops similar to those used to develop the Road Map will be held in Townsville, Sydney, Melbourne, Alice Springs and Perth during May 2008. Participants will be invited to provide information on their use of the Road Map and its perceived impact, and whether or not the research themes are still valid and important. The NHMRC welcomes the participation of individuals and organisations at these workshops and in a written submission process.

Details of the workshops and the written submission process can be found at the NHMRC website (http://www.nhmrc.gov.au) or by contacting Cathy Mitchell, Director of Strategic Partnerships, on(02)62179384 or cathy.mitchell@nhmrc.gov.au.

\section{Author details}

Felicia R Fletcher, MAPublicLaw, Assistant Director ${ }^{1}$

Cindy Shannon, BA, MBA, DSocSc, Professor and Director, ${ }^{2}$ and Chair, Aboriginal and Torres Strait Islander Health and Research Advisory Committee $^{1}$

Terry E Dunbar, BBus, MPET, Associate Professor and Senior Research Fellow $^{3}$

1 National Health and Medical Research Council, Canberra, ACT.

2 Centre for Indigenous Health, University of Queensland, Brisbane, QLD.

3 School of Education and Graduate School for Health Practice, Charles Darwin University, Darwin, NT.

Correspondence: felicia.fletcher@nhmrc.gov.au

\section{References}

1 Calma T, Aboriginal and Torres Strait Islander Social Justice Commissioner. Social justice report 2005. Chapter 2: Achieving Aboriginal and Torres Strait Islander health equality within a generation - a human rights based approach. Sydney: Human Rights and Equal Opportunity Commission, 2005. http://www.hreoc.gov.au/social_justice/health/ health_summary.html (accessed Apr 2008).

2 National Health and Medical Research Council. The NHMRC Road Map: a strategic framework for improving Aboriginal and Torres Strait Islander health through research. Canberra: NHMRC, 2002. http:// www.nhmrc.gov.au/publications/synopses/r28syn.htm (accessed Mar 2008).

3 National Health and Medical Research Council. National statement on ethical conduct in research involving humans. Canberra: NHMRC, 1999. http://www.nhmrc.gov.au/publications/humans/contents.htm (accessed Mar 2008)

4 National Health and Medical Research Council. Values and ethics: guidelines for ethical conduct in Aboriginal and Torres Strait Islander health research. Canberra: NHMRC, 2003. http://www.nhmrc.gov.au/ publications/synopses/e52syn.htm (accessed Mar 2008).

5 National Health and Medical Research Council. Keeping research on track: a guide for Aboriginal and Torres Strait Islander peoples about health research ethics. Canberra: NHMRC, 2006. http:// www.nhmrc.gov.au/publications/synopses/e65syn.htm (accessed Mar 2008).

(Received 18 Mar 2008, accepted 26 Mar 2008) 